\title{
Lobbying Expenditures of the Health Sector During the COVID-19 Pandemic
}

J Gen Intern Med 35(10):3133-6

DOI: $10.1007 / \mathrm{s} 11606-020-06085-6$

(c) Society of General Internal Medicine 2020

\section{INTRODUCTION}

As of June 30, 2020, Congress had enacted six bills authorizing approximately $\$ 3$ trillion in COVID-19 pandemic relief, representing the largest relief package in US history. The bills allocate funds to federal agencies, health care providers, COVID-19 testing, Medicaid funding, stimulus checks, unemployment benefits, and small business assistance, among other purposes. ${ }^{1}$ Prior research has found that health care organizations spend substantial financial resources on influencing legislative outcomes. ${ }^{2,3}$ In this study, we examine lobbying efforts of the health sector relative to other sectors before and during the COVID-19 pandemic.

\section{METHODS}

On July 16, 2020, all quarterly lobbying reports and lobbying registration reports (required any time an organization hires a new lobbying firm) were obtained for the period between Q1 2018 and Q1 2020 from the Senate's Lobbying Disclosure Database. ${ }^{4}$ Based on their primary Standard Industrial Classification Code from Compustat and hand collections for nonCompustat entities, ${ }^{5}$ organizations were categorized as health sector and non-health sectors, and the health sector organizations were further divided into 14 segments. Two authors independently categorized non-Compustat organizations and reconciled the results through consensus.

A lobbying report usually includes multiple issues. If an issue description contained "corona," or "COVID", or mentions the six bills related to COVID-19, its lobbying amount (amount from the lobbying report divided by the number of issues reported) was identified as related to COVID-19, consistent with the lobbying literature. ${ }^{6}$ For robustness, all COVID-19-related issues that also contained variations of "Part D reform" or "surprise billing" (the two subjects commonly mentioned in Q1 2020 health-related lobbying reports)

Received July 2, 2020

Accepted July 27, 2020

Published online August 12, 2020 were excluded. COVID-19-related new lobbying registrations were identified similarly. This identification methodology conservatively estimated the lower-bound for COVID-19related lobbying efforts.

The total and estimated COVID-19-specific lobbying expenditures were aggregated for each organization. The quarterly lobbying expenditures and new lobbying registrations were analyzed for health and non-health sectors. The 30 health care organizations with the highest lobbying expenditures in Q1 2020 were identified.

\section{RESULTS}

For both health and non-health sectors, lobbying expenditures and new lobbying registrations were higher in the first quarters than in other quarters from 2018 to 2020, and highest in Q1 2020. In Q1 2020, the health sector spent $\$ 248.4$ million on lobbying and filed 357 new lobbying registrations, representing $22.7 \%$ of all lobbying and $22.6 \%$ of all new lobbying registrations, the highest totals and percentages among the nine consecutive quarters (Fig. 1). The health sector lobbying spending increased $10.1 \%$ in Q1 2020 while non-health sector increased only $1.2 \%$. The health sector lobbying registrations increased $139.6 \%$ while non-health sector increased $63.3 \%$. Based on conservative estimates, the health sector spent $\$ 63.0$ million on COVID-19 lobbying (24.8\% of all COVID-19 lobbying) and filed 138 new lobbying registrations directly related to COVID-19 (21.8\% of all COVID-19 lobbying registrations) in Q1 2020.

Four segments - pharmaceutical (37.5\%), hospital (12.7\%), health insurance $(11.5 \%)$, and professional services (9.0\%) -accounted for $70.7 \%$ of the lobbying expenditures in the health sector. For COVID-19 lobbying, these segments accounted for $64.2 \%(26.4 \%, 13.4 \%, 12.0 \%$, and $12.4 \%$, respectively) of such expenditures. The top 30 health care organizations spent $\$ 99.5$ million on lobbying in Q1 2020 (40.1\% of the health sector total), including \$21.6 million for COVID-19 lobbying (34.4\% of the health sector total) (Table 1). On average, these 30 organizations spent 55\% more on lobbying in Q1 2020 than in Q4 2019. Among them, 16 were in the pharmaceutical segment. The Pharmaceutical Research and Manufacturers of America was the largest spender ( $\$ 11.5$ million) in the health sector. 
a Lobbying Expenditures

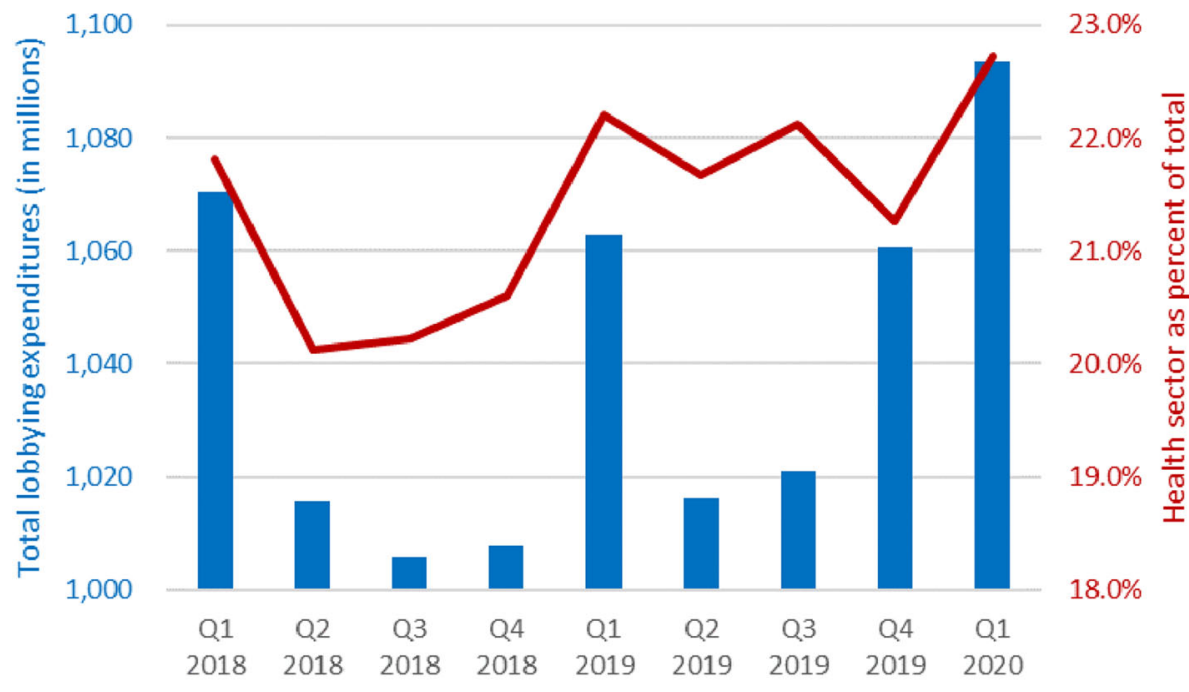

b New Lobbying Registrations

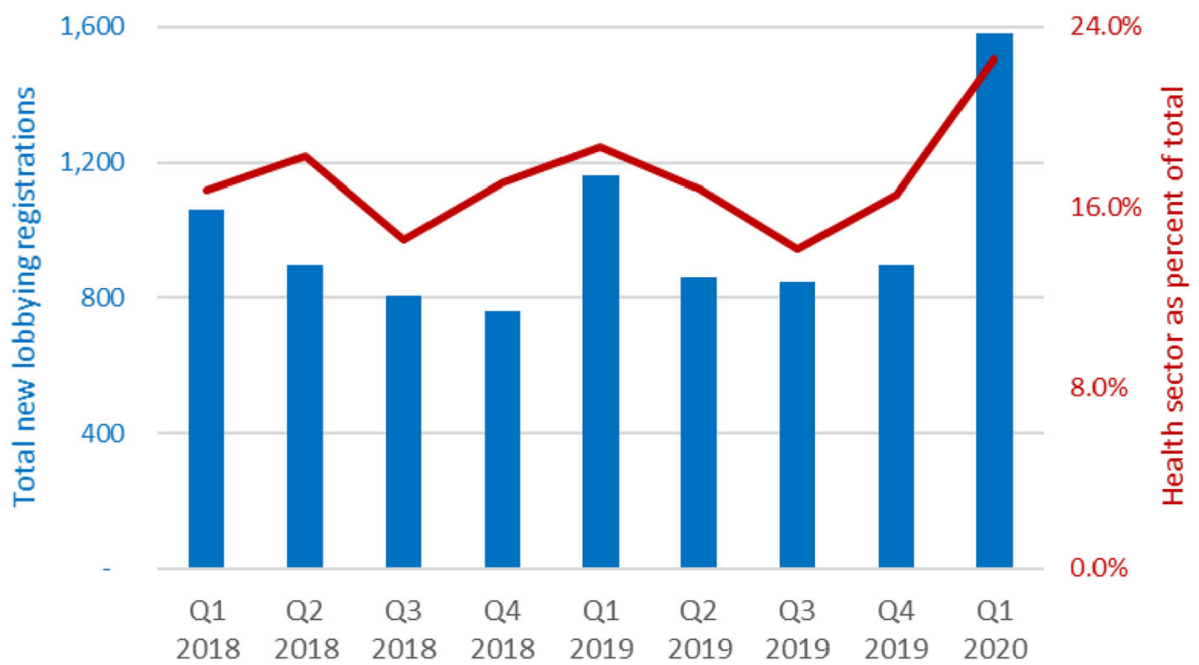

Figure 1 Lobbying expenditure and new lobbying registrations, Q1 2018-Q1 2020. a Lobbying expenditures. b New lobbying registrations.

\section{DISCUSSION}

This study provides new evidence of the health sector's influence on the US legislative process. The health sector's lobbying expenditures (\$248.4 million) and new lobbying registrations (357) reached $22.7 \%$ and $22.6 \%$ among all sectors in Q1 2020, surpassing previous eight quarters. These results illustrated the health sector's increased efforts - in both absolute and relative terms (as compared with non-health sectors) - to influence Congress' appropriation and allocation of COVID-19 relief.
This study, limited to lobbying expenditures and new lobbying registrations, reflects only a fraction of the industry influence. The COVID-19-specific lobbying expenditures have substantial measurement noise. Due to the varying nature of relief funds, the unavailability of certain allocation details, and the long-term effects accrued by cumulative lobbying efforts, quantifying the consequences of lobbying efforts is beyond the scope of this study and warrants future exploration. 
Table 1 Top 30 Health Care Organizations with the Highest Lobbying Expenditures, Q1 2020

\begin{tabular}{|c|c|c|c|c|c|c|c|}
\hline \multicolumn{2}{|l|}{ Ranking } & \multicolumn{2}{|l|}{ Organizations } & \multicolumn{4}{|c|}{ Lobbying expenditure (in millions) } \\
\hline Q1 2020 & Q4 2019 & Name & Segment & Q1 2020 & Q4 2019 & $\%$ change & COVID-19 \\
\hline 1 & 1 & PhRMA & Pharmaceutical & $\$ 11.51$ & $\$ 8.88$ & $30 \%$ & $\$ 0.43$ \\
\hline 2 & 4 & American Medical Association & Professional services & $\$ 6.88$ & $\$ 4.20$ & $64 \%$ & $\$ 3.07$ \\
\hline 3 & 3 & American Hospital Association & Hospital & $\$ 6.31$ & $\$ 6.99$ & $-10 \%$ & $\$ 0.11$ \\
\hline 4 & 2 & Blue Cross Blue Shield Companies & Health insurance & $\$ 5.67$ & $\$ 7.28$ & $-22 \%$ & $\$ 1.43$ \\
\hline 5 & 7 & Pfizer Inc. & Pharmaceutical & $\$ 5.13$ & $\$ 3.28$ & $56 \%$ & $\$ 0.30$ \\
\hline 6 & 10 & Americas Health Insurance Plans & Health insurance & $\$ 4.05$ & $\$ 2.75$ & $47 \%$ & $\$ 2.22$ \\
\hline 7 & 8 & CVS Corporation & Pharmacy & $\$ 4.05$ & $\$ 2.98$ & $36 \%$ & $\$ 0.59$ \\
\hline 8 & 5 & Amgen Inc. & Pharmaceutical & $\$ 3.93$ & $\$ 3.61$ & $9 \%$ & $\$ 0.32$ \\
\hline 9 & 44 & Novartis International & Pharmaceutical & $\$ 3.76$ & $\$ 1.05$ & $259 \%$ & $\$ 0.58$ \\
\hline 10 & 13 & Genentech, Inc. & Pharmaceutical & $\$ 3.61$ & $\$ 2.43$ & $49 \%$ & $\$ 1.05$ \\
\hline 11 & 6 & Biotechnology Innovation Organization & Pharmaceutical & $\$ 3.38$ & $\$ 3.56$ & $-5 \%$ & $\$ 2.14$ \\
\hline 12 & 32 & AbbVie Inc. & Pharmaceutical & $\$ 3.32$ & $\$ 1.30$ & $155 \%$ & $\$ 0.03$ \\
\hline 13 & 16 & Gilead Sciences, Inc. & Pharmaceutical & $\$ 3.16$ & $\$ 2.04$ & $55 \%$ & $\$ 0.61$ \\
\hline 14 & 20 & Air Medical Group Holdings & Ambulance & $\$ 2.70$ & $\$ 1.81$ & $49 \%$ & $\$-$ \\
\hline 15 & 26 & Merck \& Co., Inc. & Pharmaceutical & $\$ 2.70$ & $\$ 1.55$ & $74 \%$ & $\$ 0.60$ \\
\hline 16 & 22 & Aflac Inc. & Health insurance & $\$ 2.60$ & $\$ 1.77$ & $47 \%$ & $\$-$ \\
\hline 17 & 12 & Bayer Corporation & Pharmaceutical & $\$ 2.57$ & $\$ 2.50$ & $3 \%$ & $\$ 0.71$ \\
\hline 18 & 23 & GE Healthcare & Medical devices & $\$ 2.56$ & $\$ 1.75$ & $46 \%$ & $\$ 0.52$ \\
\hline 19 & 11 & AdvaMed & Medical devices & $\$ 2.13$ & $\$ 2.63$ & $-19 \%$ & $\$ 0.90$ \\
\hline 20 & 37 & Sanofi S.A. & Pharmaceutical & $\$ 2.12$ & $\$ 1.20$ & $77 \%$ & $\$ 0.35$ \\
\hline 21 & 17 & Johnson and Johnson & Medical devices & $\$ 2.03$ & $\$ 1.94$ & $5 \%$ & $\$ 0.38$ \\
\hline 22 & 25 & UnitedHealth Group Incorporated & Health insurance & $\$ 2.01$ & $\$ 1.64$ & $23 \%$ & $\$ 0.09$ \\
\hline 23 & 27 & Horizon Therapeutics PLC & Pharmaceutical & $\$ 1.82$ & $\$ 1.49$ & $22 \%$ & $\$ 0.84$ \\
\hline 24 & 19 & Fresenius Medical Care & Dialysis & $\$ 1.82$ & $\$ 1.82$ & $0 \%$ & $\$ 1.52$ \\
\hline 25 & 63 & AstraZeneca plc & Pharmaceutical & $\$ 1.80$ & $\$ 0.71$ & $154 \%$ & $\$ 0.67$ \\
\hline 26 & 47 & Davita Inc. & Dialysis & $\$ 1.75$ & $\$ 0.99$ & $77 \%$ & $\$ 1.13$ \\
\hline 27 & 14 & Eli Lilly and Company & Pharmaceutical & $\$ 1.66$ & $\$ 2.18$ & $-24 \%$ & $\$ 0.17$ \\
\hline 28 & 28 & Alkermes plc & Pharmaceutical & $\$ 1.54$ & $\$ 1.44$ & $7 \%$ & $\$ 0.04$ \\
\hline 29 & 128 & Biogen Inc. & Pharmaceutical & $\$ 1.51$ & $\$ 0.34$ & $344 \%$ & $\$ 0.39$ \\
\hline \multirow[t]{2}{*}{30} & 46 & Walgreens Company & Pharmacy & $\$ 1.51$ & $\$ 1.00$ & $51 \%$ & $\$ 0.46$ \\
\hline & & & Total & $\$ 99.53$ & $\$ 77.06$ & $55 \%^{\mathrm{a}}$ & $\$ 21.64$ \\
\hline
\end{tabular}

PhRMA, Pharmaceutical Research and Manufacturers of America

${ }^{a} 55 \%$ is the average of the percentages presented above

Adam Olson, $\mathrm{PhD}, \mathrm{CPA}^{1}$

John Barrick, $P h D, C P A^{2}$

William B. Tayler, $P h D, C M A^{2}$

Shivaram Rajgopal, $\mathrm{PhD}^{3}$

Ge Bai, PhD, CPA ${ }^{4}$

${ }^{1}$ Carl H. Lindner College of Business, University of Cincinnati,

Cincinnati, $\mathrm{OH}$, USA

${ }^{2}$ Marriott School of Business, Brigham Young University,

Provo, UT, USA

${ }^{3}$ Columbia Business School,

New York, NY, USA

${ }^{4}$ Johns Hopkins Carey Business School, Johns Hopkins Bloomberg School of Public Health,

Baltimore, Maryland, United States
Corresponding Author: Ge Bai, PhD, CPA; Johns Hopkins Carey Business School, Johns Hopkins Bloomberg School of Public HealthBaltimore, Maryland, United States (e-mail: gbai@jhu.edu).

Funding Information John Barrick and William Tayler received funding from the BYU Healthcare Industry Research Collaborative.

\section{Compliance with Ethical Standards:}

Conflict of Interest: The authors declare that they do not have a conflict of interest.

\section{REFERENCES}

1. United States Congress. H.R.6074 - Coronavirus Preparedness and Response Supplemental Appropriations Act, 2020. https://www.congress.gov/bill/116th-congress/house-bill/6074. H.R.6201 - Families First Coronavirus Response Act. https://www.congress.gov/bill/116th- 
congress/house-bill/6201. H.R.748 - CARES Act. https://www.congress. gov/bill/116th-congress/house-bill/748. H.R.266 - Paycheck Protection Program and Health Care Enhancement Act. https://www.congress.gov/ bill/116th-congress/house-bill/266. H.R.6322 - Student Veteran Coronavirus Response Act of 2020. https://www.congress.gov/bill/116th-congress/house-bill/6322. H.R.7010 - Paycheck Protection Program Flexibility Act of 2020. https://www.congress.gov/bill/116th-congress/ house-bill/7010. Accessed Jun 12, 2020

2. Wouters OJ. Lobbying expenditures and campaign contributions by the pharmaceutical and health-product industry in the United States. 19992018. JAMA Intern Med. 2020;180(5):1-10. doi: https://doi.org/10.1001/ jamainternmed.2020.0146

3. Steinbrook R. Lobbying, campaign contributions, and health care reform. $N$ Engl J Med. 2009;361(23):e52. doi:https://doi.org/10.1056/ NEJMp0910879
4. United States Senate. Downloadable lobbying databases. https://www. senate.gov/legislative/Public_Disclosure/database_download.htm. Accessed Jul 16, 2020.

5. Standard \& Poor's Global Market Intelligence. Compustat. http://www. compustat.com. Accessed Jul 16, 2020.

6. Barrick J, Brown J. Tax-related corporate political activity research: a literature review. Journal of the American Taxation Association. 2019;41(1):59-89. doi:https://doi.org/10.2308/atax-52026

Publisher's Note: Springer Nature remains neutral with regard to jurisdictional claims in published maps and institutional affiliations. 